\title{
Ferrimagnetism as a consequence of unusual cation ordering in the perovskite $\mathrm{SrLa}_{2} \mathrm{FeCoSbO}_{9}$
}

\author{
Yawei Tang, Emily C. Hunter and Peter D. Battle
}

Inorganic Chemistry Laboratory, University of Oxford, South Parks Road, Oxford, OX1 3QR, $U . K$.

Mylène Hendrickx and Joke Hadermann

EMAT, University of Antwerp, Groenenborgerlaan 171, 2020 Antwerp, Belgium

\section{J. M. Cadogan}

School of Physical, Environmental and Mathematical Sciences, UNSW Canberra at the Australian Defence Force Academy, Canberra BC 2610, Australia

* author to whom correspondence should be addressed: peter.battle@chem.ox.ac.uk 


\begin{abstract}
A polycrystalline sample of $\mathrm{SrLa}_{2} \mathrm{FeCoSbO}_{9}$ has been prepared in a solid-state reaction and studied by a combination of electron microscopy, magnetometry, Mössbauer spectroscopy, $\mathrm{X}$-ray diffraction and neutron diffraction. The compound adopts a monoclinic (space group $P 2_{1} / n ; a=5.6218(6), b=5.6221(6), c=7.9440(8) \AA, \beta=90.050(7){ }^{\circ}$ at $\left.300 \mathrm{~K}\right)$ perovskitelike crystal structure with two crystallographically distinct six-coordinate sites. One of these sites is occupied by $2 / 3 \mathrm{Co}^{2+}, 1 / 3 \mathrm{Fe}^{3+}$ and the other by $2 / 3 \mathrm{Sb}^{5+}, 1 / 3 \mathrm{Fe}^{3+}$. This pattern of cation ordering results in a transition to a ferrimagnetic phase at $215 \mathrm{~K}$. The magnetic moments on nearest-neighbour, six-coordinate cations align in an antiparallel manner and the presence of diamagnetic $\mathrm{Sb}^{5+}$ on only one of the two sites results in a non-zero remanent magnetisation of $\sim 1 \mu_{\mathrm{B}}$ per formula unit at $5 \mathrm{~K}$.
\end{abstract}

\title{
Introduction
}

Oxides with perovskite-type crystal structures have been attracting interest for decades because of the various applications they have in different areas of technology ${ }^{1}$. The diverse properties that give rise to this range of functionalities results firstly from the ability of the structure to distort away from the cubic ideal and to adopt instead trigonal, tetragonal or even lower symmetries. The second important factor is that the structure can accommodate a wide variety of different elements. The simplest perovskites with oxygen as the anion can be represented by the formula $A B O_{3}$, where $A$ is a relatively large cation, usually an s-block or $f$ block element, that occupies the twelve-coordinate $A$ site, and $B$ is a smaller cation, usually a $d$-block or $p$-block element, that occupies the six-coordinate B site. Partial cation substitution at either or both of the A site and the B site is one of the key strategies that has been used to introduce sought-after functionality. This results in compositions that must be described using more complex formulae, for example $A A^{\prime} B B^{\prime} \mathrm{O}_{6}$ and $A_{2} A^{\prime} B_{2} B^{\prime} \mathrm{O}_{9}{ }^{2,}{ }^{3}$. The different cations on, for example, the octahedral site can occupy that site in an ordered or disordered manner. Ordering is most likely to occur when the ions differ significantly in charge or size and ordering on the B site is therefore observed more often than ordering on the A site. This ordering is highly significant because it can control the distortion away from cubic symmetry and consequently the magnetic properties of the compound.

We have previously described a perovskite, $\mathrm{La}_{3} \mathrm{Ni}_{2} \mathrm{SbO}_{9}$, that behaves as a relaxor ferromagnet ${ }^{4,5}$ below $110 \mathrm{~K}$. This compound adopts a monoclinic structure in which two crystallographically-distinct $\mathrm{B}$ sites occur in a 1:1 ratio. One of the sites is occupied only by 
$\mathrm{Ni}^{2+}$ cations while $2 / 3$ of the second type of site are occupied by $\mathrm{Sb}^{5+}$, with the remainder being occupied by $\mathrm{Ni}^{2+}$. The difference in the concentration of magnetic $\mathrm{Ni}^{2+}$ cations on the two sites is the cause of the ferrimagnetic behaviour observed, although local irregularities in the cation distribution cause the formation of magnetic microdomains and, consequently, the absence of magnetic Bragg scattering from the neutron diffraction pattern recorded below the transition temperature. Hence the compound can be classified as a relaxor. $\mathrm{La}_{3} \mathrm{Co}_{2} \mathrm{SbO}_{9}$ shows the same cation ordering pattern as $\mathrm{La}_{3} \mathrm{Ni}_{2} \mathrm{SbO}_{9}$ but the sharp increase in magnetisation observed in the latter at $108 \mathrm{~K}$ is not observed in the former ${ }^{6}$. Franco et al. postulated that frustration prevents the development of long-range ferromagnetism and their neutron diffraction data, collected at $2 \mathrm{~K}$, contained a magnetic Bragg peak which they took to be indicative of an unidentified antiferromagnetically-ordered structure. They have also studied ${ }^{7}$ the system $\mathrm{La}_{3} \mathrm{Ni}_{2-\mathrm{y}} \mathrm{Co}_{\mathrm{y}} \mathrm{SbO}_{9}$ wherein they found a similarly-ordered distribution of cations but no evidence for long-range magnetic ordering.

In general, magnetic transition temperatures are expected to be highest in the members of an isostructural series that contain the most strongly magnetic cations. In an attempt to prepare a relaxor ferromagnet with an enhanced transition temperature we have previously synthesized $\mathrm{Fe}^{3+}$-containing analogues of $\mathrm{La}_{3} \mathrm{Ni}_{2} \mathrm{SbO}_{9}$, for example $\mathrm{Sr}_{3} \mathrm{Fe}_{2} \mathrm{TeO}_{9}$. However, the majority of the $\mathrm{Fe}^{3+}$ and $\mathrm{Te}^{6+}$ cations in this compound adopt an unusual 2:1 ordering pattern over the $\mathrm{B}$ sites that, in turn, leads to the adoption of an unusual antiferromagnetic structure ${ }^{8}$; neither ferrimagnetism nor relaxor behaviour were observed. We have now prepared compositions in which only $1 / 3$ of the $\mathrm{B}$ sites are occupied by $\mathrm{Fe}^{3+}$, for example $\mathrm{ALa}_{2} \mathrm{FeCoSbO}_{9}$ and $\mathrm{ALa}_{2} \mathrm{FeNiSbO}_{9}(A=\mathrm{Ba}, \mathrm{Sr}, \mathrm{Ca})$. In this paper we describe the synthesis and characterisation of one such compound that shows particularly interesting behaviour; the more complex and varied properties of the other members of the series will be described in a later publication. More specifically, we describe below how a combination of X-ray and neutron diffraction, magnetometry, electron microscopy and Mössbauer spectroscopy has revealed a novel cation-ordering pattern and consequential ferrimagnetism in $\mathrm{SrLa}_{2} \mathrm{FeCoSbO}_{9}$.

\section{Experimental}

A polycrystalline sample of $\mathrm{SrLa}_{2} \mathrm{FeCoSbO}_{9}$ was prepared using the standard ceramic method. $\mathrm{SrCO}_{3}, \mathrm{La}_{2} \mathrm{O}_{3}, \mathrm{Fe}_{2} \mathrm{O}_{3}, \mathrm{Co}_{3} \mathrm{O}_{4}$ and $\mathrm{Sb}_{2} \mathrm{O}_{5}$ (purity $>99.95 \%$ ) were weighed out in the appropriate stoichiometric ratio and ground together in an agate mortar for 30 minutes to give a homogeneous mixture. $\mathrm{La}_{2} \mathrm{O}_{3}$ was heated at $800{ }^{\circ} \mathrm{C}$ for 24 hours prior to use to ensure it was completely dry. The mixture was then loaded into an alumina crucible and fired at 800 
${ }^{\circ} \mathrm{C}$ for $24 \mathrm{~h}$. It was then quenched to room temperature, reground and pressed into a pellet which was fired in air at $1300{ }^{\circ} \mathrm{C}$ for 48 hours and subsequently annealed at $1300{ }^{\circ} \mathrm{C}$ for another 48 hours after further grinding. Finally, the furnace was allowed to cool to $800{ }^{\circ} \mathrm{C}$ and then the sample was quenched to room temperature.

The brown-black reaction product was initially characterised by X-ray powder diffraction (XRPD) using $\mathrm{Cu} \mathrm{K} \alpha_{1}$ radiation. The data, collected at room temperature on a Panalytical $X$ 'Pert diffractometer, were analysed using the Rietveld method ${ }^{9}$ as implemented in the GSAS $^{10}$ program package. Neutron diffraction patterns were collected from the reaction product at $5 \mathrm{~K}$ and $300 \mathrm{~K}$ on the GEM time-of-flight diffractometer at the ISIS spallation source with the sample contained in a vanadium can. The data collected on detector banks at scattering angles, $2 \theta$, of $34.96^{\circ}, 63.62^{\circ}, 91.30^{\circ}$ and $154.40^{\circ}$ were analysed simultaneously using GSAS.

$\mathrm{SrLa}_{2} \mathrm{FeCoSbO}_{9}$ was also studied by transmission electron microscopy (TEM). The specimens for TEM were prepared by dispersing crushed powder in ethanol and depositing a few drops of this solution on a copper grid covered with a holey carbon film. Selected area electron diffraction (SAED) patterns were recorded with a Philips CM20 microscope. Highangle annular dark-field STEM (HAADF-STEM) images and energy-dispersive X-ray (EDX) maps were acquired with a FEI Titan 80-300 “cubed” microscope equipped with a Super-X detector and operated at $300 \mathrm{kV}$.

${ }^{57} \mathrm{Fe}$ Mössbauer spectroscopy was carried out on finely ground $\mathrm{SrLa}_{2} \mathrm{FeCoSbO}_{9}$ at room temperature $(295 \mathrm{~K})$ in a standard, transmission-mode spectrometer using a ${ }^{57} \mathrm{CoRh}$ source. The velocity scale of the spectrometer was calibrated using a $6 \mu \mathrm{m}$ thick $\alpha$-Fe foil and all isomer shifts quoted herein are relative to the centre of the $\alpha$-Fe calibration spectrum. All Mössbauer spectra were fitted using the NORMOS software ${ }^{11}$.

The dc molar magnetic susceptibility of the product was measured over the temperature range $2<\mathrm{T} / \mathrm{K}<370$ using a Quantum Design MPMS 5000 SQUID magnetometer. Data were collected on warming in a field of 100 Oe after cooling the sample both in the absence of an applied field (zero-field cooled, ZFC) and in the measuring field (field cooled, FC). The isothermal magnetisation was measured as a function of field over the range $-50<\mathrm{H} / \mathrm{kOe}<$ 50 at 300 and $5 \mathrm{~K}$ after cooling in a field of $50 \mathrm{kOe}$. The ac susceptibility of $\mathrm{SrLa}_{2} \mathrm{FeCoSbO}_{9}$ was measured over the temperature range $50<\mathrm{T} / \mathrm{K}<300$ in a field of amplitude 3.5 Oe oscillating at frequencies of 1, 10, 100 and $1000 \mathrm{~Hz}$. 


\section{Results}

The XRPD pattern of the reaction product suggested that the synthesis had produced a phasepure pseudo-cubic perovskite. The XRD pattern was indexed and analysed in the primitive monoclinic space group $P 2_{1} / n$ with $a \sim \sqrt{ } 2 a_{\mathrm{p}}, b \sim \sqrt{ } 2 a_{\mathrm{p}}$ and $c \sim 2 a_{\mathrm{p}}$, where $a_{\mathrm{p}}$ is the unit cell parameter of a primitive cubic perovskite. The fit to the observed pattern is shown in Figure 1. In this space group the structural model, see Figure 2, involves a $4 e$ site that accommodates a disordered distribution of $\mathrm{Sr}$ and $\mathrm{La}$, three further $4 e$ sites that accommodate oxide ions and two independent B sites, $2 d(1 / 2,0,0)$ and $2 c(0,1 / 2,0)$ which accommodate the three cation species $\mathrm{Fe}^{3+}, \mathrm{Co}^{2+}$ and $\mathrm{Sb}^{5+}$. The X-ray scattering lengths of iron and cobalt are very similar and it was impossible to distinguish between these two elements using our X-ray data. In this analysis they were therefore treated as if they were identical. Refinements of the distribution of a representative transition metal and antimony over the crystallographically-distinct B sites showed that the $2 d(1 / 2,0,0)$ sites are largely occupied by transition metals, while nearly all the antimony atoms are on the $2 c(0,1 / 2,0)$ sites; the fit to the data shown in Figure 1 is based on the refined cation distribution $\mathrm{SrLa}_{2}\left(\mathrm{Fe} / \mathrm{Co}_{1.42} \mathrm{Sb}_{0.08}\right)_{2 \mathrm{~d}}\left(\mathrm{Fe} / \mathrm{Co}_{0.58} \mathrm{Sb}_{0.92}\right)_{2 \mathrm{c}} \mathrm{O}_{9}$. Although they did not establish the distribution of iron and cobalt, our XRPD data enabled us to establish the space group symmetry of the compound and that essentially all the antimony is located on a single six-coordinate site.

The time-of-flight neutron diffraction patterns collected from $\mathrm{SrLa}_{2} \mathrm{FeCoSbO}_{9}$ at $300 \mathrm{~K}$ were analysed using the structural model derived from the XRPD data as a starting point. After some preliminary refinements, the antimony occupancy of the $2 d$ site of $\mathrm{SrLa}_{2} \mathrm{FeCoSbO}_{9}$ was fixed to zero. We were then able to allow the distribution of cobalt and iron atoms over the $2 c$ and $2 d$ sites to vary, provided that the overall composition was held constant. The occupancy of cobalt on the $2 c$ site refined to zero, and the iron atoms were found to be equally distributed over the two sites. The formula of this compound is thus best written as $\mathrm{SrLa}_{2}\left(\mathrm{Fe}_{0.5} \mathrm{Co}\right)_{2 d}\left(\mathrm{Fe}_{0.5} \mathrm{Sb}\right)_{2 \mathrm{c}} \mathrm{O}_{9}$. The fit to the pattern collected at $2 \theta=34.96^{\circ}$ can be seen in Figure 3(a) and Figure 3(b) shows the fit to the data collected at $2 \theta=91.30^{\circ}$; the latter have a higher resolution but cover a more limited range of $d$-spacing. There was no evidence of long-range magnetic ordering in this compound at $300 \mathrm{~K}$. The refined structural parameters are listed in Table 1 and the most important bond lengths and angles are presented in Table 2. This structural model is consistent with the results from our electron microscopy study. Lowmagnification EDX confirmed the homogeneous distribution over the crystallites of both the A cations ( $\mathrm{Sr}, \mathrm{La}$ ) and the $\mathrm{B}$ cations (Fe, $\mathrm{Co}, \mathrm{Sb}$ ), with an average composition of $\mathrm{Sr}_{0.37(2)} \mathrm{La}_{0.63(2)} \mathrm{Fe}_{0.30(2)} \mathrm{Co}_{0.32(2)} \mathrm{Sb}_{0.32(2)}$. The different SAED patterns (representative patterns 
are shown in Figure 4) are consistent with the monoclinic space group $P 2_{1} / n$. The highresolution HAADF-STEM images (Figure 5) show the expected order at the positions of the B-cations. In such images, the intensity of the atom columns is proportional to the atomic number of the elements: $\mathrm{I} \sim \mathrm{Z}^{2}$. The continuous rows of bright dots along the $a$ or $b$-axis correspond to the (La,Sr) atom columns. Parallel to these, there are rows with an alternation of brighter and darker dots: these correspond to the alternating (Sb,Fe) and (Co,Fe) atom columns respectively. In addition, when viewed along the [100] zone axis, the A site columns are slightly shifted along [010] in an alternating sense, in agreement with the $P 2_{1} / n$ model. Atomic-resolution EDX (Figure 6) shows the ordering of Sb and Co over the $2 d$ and 2c positions of this $P 2_{1} / n$ model, while Fe is present on both sites.

In Figure 7(a) we show the room temperature Mössbauer spectrum of $\mathrm{SrLa}_{2} \mathrm{FeCoSbO}_{9}$ acquired over a large velocity range of around $\pm 11.5 \mathrm{~mm} / \mathrm{s}$. This spectrum confirms the absence of an ordered magnetic moment on the Fe at 295 K. In Figure 7(b) we show the room temperature Mössbauer spectrum of $\mathrm{SrLa}_{2} \mathrm{FeCoSbO}_{9}$ acquired over a narrower velocity range of around $\pm 4.8 \mathrm{~mm} / \mathrm{s}$. To be consistent with the EDX and diffraction data described above, this spectrum was fitted with two doublets, although the local environments of the Fe atoms on the $2 c$ and $2 d$ sites in the $\mathrm{SrLa}_{2} \mathrm{FeCoSbO}_{9}$ structure are clearly very similar from a Mössbauer perspective. The diffraction data show that the Fe cations occupy the two crystallographic sites with equal Fe occupancies. Hence, a basic modelling of the room temperature Mössbauer spectrum is based on two quadrupole-split doublets with equal spectral areas. In this situation it is impossible to obtain a unique, unambiguous fit to the spectrum due to the fact that there are three possible line-pairings of the four equal-area lines that make up the two doublets. A spectral fit in which the relative areas of the two doublets were unconstrained resulted in an area ratio of 44(5):56(5) \%. Modelling the spectrum with the area ratio constrained to be 50:50\%, consistent with the model used in the analysis of the neutron diffraction data, yields the hyperfine parameters listed in Table 3 for each of the three possible line-pairings; the fit to the spectrum is shown in Figure 7(b). Despite the ambiguity in the Mössbauer fitting, one can state that in all cases the refined values of the isomer shifts (IS) and quadrupole splittings (QS) are characteristic of $\mathrm{Fe}^{3+}$ and that the spectrum showed no evidence of magnetic hyperfine splitting.

The temperature dependence of the dc molar magnetic susceptibility of $\mathrm{SrLa}_{2} \mathrm{FeCoSbO}_{9}$ is shown in Figure 8, along with the field dependence of the magnetisation as measured at 300 $\mathrm{K}$ and $5 \mathrm{~K}$. The ZFC and FC susceptibilities both suggest that a magnetic phase transition occurs at $\sim 200 \mathrm{~K}$, although the two curves do not overlie below $\sim 350 \mathrm{~K}$. The non-linearity of 
$M(H)$ at $300 \mathrm{~K}$ provides further evidence that this compound is not a simple paramagnet at room temperature. No remanent magnetisation could be detected at $300 \mathrm{~K}$ but at $5 \mathrm{~K} M(H)$ shows a remanent magnetisation of $\sim 1 \mu_{\mathrm{B}}$ and a coercive field of $6.1 \mathrm{kOe}$; the magnetisation is unsaturated in a field of $50 \mathrm{kOe}$. The ac susceptibility of $\mathrm{SrLa}_{2} \mathrm{FeCoSbO}_{9}$, see Figure 9, is complex and frequency-dependent. However, the temperature of the maximum in the real part, $215 \mathrm{~K}$, is frequency-independent, suggesting that below this temperature the material is a ferro- or ferrimagnet rather than a spin glass.

Analysis of the neutron patterns collected from $\mathrm{SrLa}_{2} \mathrm{FeCoSbO}_{9}$ at $5 \mathrm{~K}$ was carried out using the structural model described above with the cation distribution over the B sites fixed to be the same as that determined from the data collected at room temperature. However, in order to model an increase in intensity of the 101 and 011 reflections it was necessary to allow for the presence of magnetic Bragg scattering. The extra intensity could be accounted for by the magnetic structure shown in Figure 10 where the mean magnetic moment on each B site is coupled in an antiparallel manner to those of the six nearest-neighbour sites. This spin arrangement is similar to that found in G-type antiferromagnets but in the present case the ordered moments on the two crystallographically-distinct sites are allowed to differ, thus leading to ferrimagnetism rather than antiferromagnetism. The refined structural parameters and bond lengths are listed in Tables 1 and 2, respectively. The fitted diffraction profiles collected at $2 \theta=34.96^{\circ}$ and $2 \theta=91.30^{\circ}$ are shown in Figure 11 . The mean moments on the $\mathrm{Fe} / \mathrm{Co}$-containing $2 d$ sites and the Fe/Sb-containing $2 c$ sites refined to values of $m_{z}=2.45(3)$

and $m_{z}=0.87(2) \mu_{\text {в }}$ per cation, respectively. Given that $\mathrm{Sb}^{5+}$ is diamagnetic, the latter value corresponds to a moment of 2.61(7) $\mu_{\mathrm{B}}$ per $\mathrm{Fe}^{3+}$ cation. Analysis of the neutron data thus leads to a description of $\mathrm{SrLa}_{2} \mathrm{FeCoSbO}_{9}$ as a ferrimagnet at $5 \mathrm{~K}$ with a net moment of 2.37(6) $\mu_{\text {B }}$ per formula unit.

\section{Discussion}

$\mathrm{SrLa}_{2} \mathrm{FeCoSbO}_{9}$ adopts a crystal structure in which two distinct six-coordinate sites with the same multiplicity must accommodate three species of cations, $\mathrm{Fe}^{3+}, \mathrm{Co}^{2+}$ and $\mathrm{Sb}^{5+}$, that are present in a 1:1:1 ratio. Our diffraction and microscopy data show that the trio of cations are distributed in a way which, to the best of our knowledge, has not been seen in any other perovskite-related compound; one site is occupied by $\mathrm{Co}^{2+}$ and $\mathrm{Fe}^{3+}$ in a 2:1 ratio and the other by $\mathrm{Sb}^{5+}$ and $\mathrm{Fe}^{3+}$ in the same ratio. As was discussed above, cations that are similar in size and charge are able to occupy a single site in a disordered manner, whereas when significant differences exist the cations must occupy distinct sites in order to satisfy their 
bonding requirements. $\mathrm{Fe}^{3+}$ is sufficiently similar to $\mathrm{Sb}^{5+}$ and $\mathrm{Co}^{2+}$ to share a site with either of them ${ }^{12,13}$. The difference in both size and charge between $\mathrm{Sb}^{5+}$ and $\mathrm{Co}^{2+}$ is larger, although they do share a site in $\mathrm{La}_{3} \mathrm{Co}_{2} \mathrm{SbO}_{9}$. However, the presence of an equal concentration of $\mathrm{Fe}^{3+}$, intermediate in both size and charge, eliminates the need for them to do so in $\mathrm{SrLa}_{2} \mathrm{FeCoSbO}_{9}$. The mean $\mathrm{Fe} / \mathrm{Co}$ - $\mathrm{O}$ bond lengths around the $2 d$ sites are, as expected, significantly longer than the mean $\mathrm{Fe} / \mathrm{Sb}-\mathrm{O}$ bond lengths around the $2 c$ sites, see Table 2; the bond angles around the latter site are closer to $90^{\circ}$ than those around the former. We note that the mean $M-\mathrm{O}$ bond lengths around the six-coordinate cation sites in $\mathrm{Sb}_{2} \mathrm{O}_{5}$, $\mathrm{Fe}_{2} \mathrm{O}_{3}$, and $\mathrm{CoO}$ are 1.992, 2.029 and $2.129 \AA$, respectively ${ }^{14-16}$. The mean $\mathrm{Sr} / \mathrm{La}-\mathrm{O}$ bond length in $\mathrm{SrLa}_{2} \mathrm{FeCoSbO}_{9}$ is $2.639 \AA$ at $300 \mathrm{~K}$, slightly larger than the mean La - O distance of $2.616 \AA$ found in $\mathrm{La}_{3} \mathrm{Co}_{2} \mathrm{SbO}_{9}{ }^{6}$. All the $\mathrm{Sr} / \mathrm{La}-\mathrm{O}$ distances contract on cooling from 300 to $5 \mathrm{~K}$ but the changes are not significant in the light of their standard deviations. Similarly, there is no significant change in the bond lengths around the $2 c$ and $2 d$ sites. However, as is to be expected, the $U_{\text {iso }}$ values all decrease on cooling, see Table 1 .

The absence of well-defined long-range magnetic order in $\mathrm{La}_{3} \mathrm{Co}_{2} \mathrm{SbO}_{9}$ and $\mathrm{La}_{3} \mathrm{Ni}_{2-y} \mathrm{Co}_{\mathrm{y}} \mathrm{SbO}_{9}$ 6, 7 was attributed to the magnetic frustration introduced by the cation-ordering pattern adopted. In the case of $\mathrm{La}_{3} \mathrm{Ni}_{2} \mathrm{SbO}_{9}$ we argued that small ferrimagnetic microdomains exist below $108 \mathrm{~K}$, but that they are too small to be detected in a zero-field neutron diffraction experiment ${ }^{4,5}$. In the case of $\mathrm{SrLa}_{2} \mathrm{FeCoSbO}_{9}, 50 \%$ of the divalent transition-metal cations have been replaced by $\mathrm{Fe}^{3+}$ in a way that eliminates the former from the antimony-containing site. The magnetometry data shown in Figures 9 and 10 suggest that this results in a transition to a ferrimagnetic state at the relatively-high temperature of $215 \mathrm{~K}$; the presence of longrange magnetic ordering is clearly demonstrated by the presence of magnetic Bragg scattering in the neutron diffraction patterns collected at $5 \mathrm{~K}$, see Figure 11. The magnetic model used to account for the magnetic scattering is essentially an antiferromagnetic G-type magnetic structure ${ }^{17}$, albeit with different ordered moments on the $2 c$ and $2 d$ sites, see Figure 10 . This difference results in a net ferrimagnetism, and the model is thus qualitatively consistent with the magnetometry data. A G-type structure occurs when antiferromagnetic superexchange between nearest-neighbour ( $\mathrm{NN}$ ) cations is the dominant magnetic interaction. If we assume that this is the only significant interaction operating in $\mathrm{SrLa}_{2} \mathrm{FeCoSbO}_{9}$ then we would expect to see a mean ordered moment of $M_{\mathrm{Fe}} / 3$ on the $2 c$ site and an antiparallel moment of $\left(M_{\mathrm{Fe}}+\right.$ $\left.2 M_{\mathrm{Co}}\right) / 3$ on the $2 d$ site, resulting in a net magnetisation of $M_{\mathrm{Co}}$ per formula unit. Here $M_{\mathrm{Fe}}$ and $M_{\mathrm{Co}}$ are the magnetic moments of $\mathrm{Fe}^{3+}$ and $\mathrm{Co}^{2+}$ which would be expected to take values of $\sim 5$ and $\sim 3 \mu_{\mathrm{B}}$, respectively. The ordered moments determined by neutron diffraction and the 
magnetisation measured in $50 \mathrm{kOe}$ are all lower than the values predicted by this simplistic model. We suggest that the presence of diamagnetic $\mathrm{Sb}^{5+}$ on $2 / 3$ of the $2 c$ sites reduces the effectiveness and dominance of the NN coupling. Although there will be antiferromagnetic $\mathrm{Fe}-\mathrm{O}-\mathrm{Fe}$ and $\mathrm{Co}-\mathrm{O}-\mathrm{Fe}$ interactions between $\mathrm{NN}$ sites, it is likely that there will also be significant next-nearest-neighbour (NNN) $90^{\circ}$ interactions along $\mathrm{Fe}-\mathrm{O}-\mathrm{O}-\mathrm{Fe}$ or $\mathrm{Fe}-\mathrm{O}$ - O - Co pathways. This type of interaction dominates in the 1:1 cation-ordered perovskite $\mathrm{SrLaNiSbO}_{6}{ }^{18}$, where it results in the adoption of a Type I antiferromagnetic structure. Furthermore, in the case of $\mathrm{Sr}_{2} \mathrm{FeSbO}_{6}$, in which the $\mathrm{Fe}^{3+}$ cations occupy the $2 c$ and $2 d$ sites in a partially ordered 14:86 ratio, the competition between $\mathrm{NN} \mathrm{Fe} \mathrm{-} \mathrm{O} \mathrm{-} \mathrm{Fe} \mathrm{and} \mathrm{NNN} \mathrm{Fe} \mathrm{-} \mathrm{O}$ - $\mathrm{O}-\mathrm{Fe}$ interactions is strong enough to result in spin-glass behaviour with a spin-freezing temperature of $\sim 36 \mathrm{~K}^{19}$. We thus attribute the low values of the mean ordered moments on the six-coordinate sites to spin disorder that is itself a consequence of the presence of a disordered distribution of $\mathrm{Sb}^{5+}$ on $2 / 3$ of the $2 c$ sites. The magnetic transition temperature of $\mathrm{SrLa}_{2} \mathrm{FeCoSbO}_{9}$ is higher than those of $\mathrm{La}_{3} \mathrm{Ni}_{2} \mathrm{SbO}_{9}$ and the other triple perovskites described above, which might in part be attributable to the large magnetic moment associated with $\mathrm{Fe}^{3+}$. It might also be significant that the NN superexchange pathways are closer to linearity in $\mathrm{SrLa}_{2} \mathrm{FeCoSbO}_{9}$ than they are in $\mathrm{La}_{3} \mathrm{Co}_{2} \mathrm{SbO}_{9}{ }^{6}$, see Table 2. Close inspection of the temperature dependence of the magnetic susceptibility and the $M(H)$ data, see Figure 8, shows that our sample is not truly paramagnetic at $300 \mathrm{~K}$. However, no hyperfine splitting was seen in the Mössbauer spectrum recorded over a wide velocity range, see Figure 7(a). Superexchange interactions between $\mathrm{NN} \mathrm{Fe}^{3+}$ cations in pseudo-cubic perovskites are known to be very strong ${ }^{20,21}$ and we suggest that the hysteresis seen in $\chi(T)$ above the Curie temperature is caused by short-range spin ordering involving some of these cations. These issues will not be resolved until further experimental work has been undertaken.

\section{Conclusions}

The six-coordinate cations in $\mathrm{SrLa}_{2} \mathrm{FeCoSbO}_{9}$ order in what is, to the best of our knowledge, a previously-unreported manner. Consequently, and unlike $\mathrm{La}_{3} \mathrm{Ni}_{2} \mathrm{SbO}_{9}, \mathrm{La}_{3} \mathrm{Co}_{2} \mathrm{SbO}_{9}$ and $\mathrm{La}_{3} \mathrm{Ni}_{2-\mathrm{y}} \mathrm{Co}_{\mathrm{y}} \mathrm{SbO}_{9}$, this compound shows clear evidence of long-range magnetic order when studied by neutron diffraction at low temperatures. The observed cation distribution, with diamagnetic $\mathrm{Sb}^{5+}$ partially occupying only one of the six-coordinate sites, results in ferrimagnetism below the Curie temperature of $215 \mathrm{~K}$. This ordering temperature is considerably higher than the temperature of the magnetic transitions observed in the other 
three compounds, perhaps as a result of the involvement of the strongly-magnetic $\mathrm{Fe}^{3+}$ cations.

\section{Acknowledgments}

PDB, ECH and JH acknowledge support from EPSRC under grant EP/M0189954/1. We would like to thank the STFC for the award of beamtime at the ISIS Neutron and Muon Source (RB 1610100) and we thank Dr I. da Silva for the assistance provided. We also thank Dr. R. Paria Sena for help with the HAADF-STEM and STEM-EDX experiments.

\section{References}

(1) Bhalla, S. A.; Guo, R.; Roy, R. The perovskite structure - a review of its role in ceramic science and technology. Mater. Res. Innovations 2000, 4, 3-26.

(2) Anderson, M. T.; Greenwood, K. B.; Taylor, G. A.; Poeppelmeier, K. R. B-Cation Arrangements in Double Perovskites. Prog. Solid State Chem. 1993, 22, 197-233.

(3) Vasala, S.; Karppinen, M. A(2)B ' B " O 6 perovskites: A review. Prog. Solid State Chem. 2015, 43, $1-36$.

(4) Battle, P. D.; Evers, S. I.; Hunter, E. C.; Westwood, M. $\mathrm{La}_{3} \mathrm{Ni}_{2} \mathrm{SbO}_{9}$ : a Relaxor Ferromagnet. Inorg. Chem. 2013, 52, 6648.

(5) Battle, P. D.; Avdeev, M.; Hadermann, J. The interplay of microstructure and magnetism in $\mathrm{La}_{3} \mathrm{Ni}_{2} \mathrm{SbO}_{9}$. J. Solid State Chem. 2014, 220, 163.

(6) Franco, D. G.; Fuertes, V. C.; Blanco, M. C.; Fernandez-Diaz, M. T.; Sanchez, R. D.; Carbonio, R. E. Synthesis, structure and magnetic properties of $\mathrm{La}_{3} \mathrm{Co}_{2} \mathrm{SbO}_{9}$ : A double perovskite with competing antiferromagnetic and ferromagnetic interactions. J. Solid State Chem. 2012, 194, 385 $-391$.

(7) Franco, D. G.; Carbonio, R. E.; Nieva, G. Synthesis and structural and magnetic characterization of the frustrated magnetic system $\mathrm{La}_{2} \mathrm{Ni}_{4 / 3-\mathrm{x}} \mathrm{Co}_{\mathrm{x}} \mathrm{Sb}_{2 / 3} \mathrm{O}_{6}$. J. Solid State Chem. 2013, 207, 69-79.

(8) Tang, Y.; Hunter, E. C.; Battle, P. D.; Paria Sena, R.; Hadermann, J.; Avdeev, M.; Cadogan, J. M. Structural chemistry and magnetic properties of the perovskite $\mathrm{Sr}_{3} \mathrm{Fe}_{2} \mathrm{TeO}_{9}$. J. Solid State Chem. 2016, 242, 86-95.

(9) Rietveld, H. M. A profile refinement method for nuclear and magnetic structures. J. Appl. Crystallogr. 1969, 2, 65 - 71.

(10) Larson, A. C.; von Dreele, R. B. General Structural Analysis System (GSAS), Los Alamos National Laboratories; LAUR 86-748; 1990.

(11) Brand, R. A. NORMOS. http://www.wissel-instruments.de/ 
(12) Battle, P. D.; Gibb, T. C.; Herod, A. J.; Kim, S.-H.; Munns, P. H. Investigation of Magnetic Frustration in $\mathrm{A}_{2} \mathrm{FeMO}_{6}(\mathrm{~A}=\mathrm{Ca}, \mathrm{Sr}, \mathrm{Ba}, \mathrm{M}=\mathrm{Nb}, \mathrm{Ta}, \mathrm{Sb})$ by Magnetometry and Mossbauer Spectroscopy. J. Mater. Chem. 1995, 5, 865.

(13) Thang, P. D.; Rijnders, G.; Blank, D. H. A. Spinel cobalt ferrite by complexometric synthesis. J. Magn. Magn. Mater. 2005, 295, 251-256.

(14) Jansen, M. Crystal Structure of $\mathrm{Sb}_{2} \mathrm{O}_{5}$. Angew. Chem.-Int. Edit. Engl. 1978, 17, 137-137.

(15) Maslen, E. N.; Streltsov, V. A.; Streltsova, N. R.; Ishizawa, N. Synchrotron X-ray Study of the Electron Density in Alpha- $\mathrm{Fe}_{2} \mathrm{O}_{3}$. Acta Crystallogr., Sect. B: Struct. Sci. 1994, 50, 435-441.

(16) Tombs, N. C.; Rooksby, H. P. Structure of Monoxides of Some Transition Elements at Low Temperatures. Nature 1950, 165, 442.

(17) Wollan, E. O.; Koehler, W. C. Neutron diffraction Study of the Magnetic Properties of the Series of Perovskite-Type Compounds [(1-x)La,xCa]MnO3. Phys. Rev. 1955, 100, 545-563.

(18) Attfield, M. P.; Battle, P. D.; Bollen, S. K.; Gibb, T. C.; Whitehead, R. J. The Crystal Structure and Magnetic Properties of $\mathrm{SrLaFeSnO}_{6}$ and $\mathrm{SrLaNiSbO}_{6}$. J. Solid State Chem. 1992, 100, 37.

(19) Battle, P. D.; Gibb, T. C.; Herold, A. J.; Hodges, J. P. Sol-Gel Synthesis of the MagneticallyFrustrated Oxides $\mathrm{Sr}_{2} \mathrm{FeSbO}_{6}$ and $\mathrm{SrLaFeSnO}_{6}$. J. Mater. Chem. 1995, 5, 75.

(20) Ivanov, S. A.; Eriksson, S. G.; Tellgren, R.; Rundlof, H. Evolution of the atomic and magnetic structure of $\mathrm{Sr}_{3} \mathrm{Fe}_{2} \mathrm{WO}_{9}$ : A temperature dependent neutron powder diffraction study. Mater. Res. Bull. 2001, 36, 2585-2596.

(21) Koehler, W. C.; Wollan, E. O. Neutron Diffraction Study of the Magnetic Properties of Perovskite-Like Compounds $\mathrm{LaBO}_{3}$. J. Phys. Chem. Solids 1957, 2, 100. 


\section{Figure Captions}

Figure 1 Observed (red) and calculated (green) X-ray powder diffraction patterns of $\mathrm{SrLa}_{2} \mathrm{FeCoSbO}_{9}$ at room temperature. A difference curve (purple) is shown and reflection positions are marked. Inset shows the splitting of peaks at lower angles.

Figure $2 \quad P 2_{1} / n$ structure adopted by $\mathrm{SrLa}_{2} \mathrm{FeCoSbO}_{9}$. Green octahedra are occupied by Fe and Co; blue octahedra by Fe and Sb. Red circles represent the Sr and La atoms at the A site.

Figure 3 Observed (red) and calculated (green) time-of-flight neutron diffraction patterns of $\mathrm{SrLa}_{2} \mathrm{FeCoSbO}_{9}$ at room temperature collected at (a) $2 \theta=34.96^{\circ}$ and (b) $2 \theta=91.30^{\circ}$. A difference curve (purple) is shown and reflection positions are marked.

Figure 4 SAED patterns of the $\mathrm{SrLa}_{2} \mathrm{FeCoSbO}_{9}$ sample along the zone axes [100], [010], [001] and [110].

Figure 5 High resolution HAADF-STEM images taken along the [100] and [010] zone axes, where red dots represent atomic columns primarily occupied by La and $\mathrm{Sr}$, blue by $\mathrm{Fe}$ and $\mathrm{Sb}$, and green by $\mathrm{Fe}$ and Co, respectively. There is a clear alternation in the grey level of the B cation columns on the HAADF-STEM images, corresponding to the different occupancies for sites $2 d$ and $2 c$.

Figure 6. High resolution HAADF-STEM image of the $\mathrm{SrLa}_{2} \mathrm{FeCoSbO}_{9}$ sample along [010] (top left) and corresponding EDX maps, showing the complementary positions of Sb and Co, with Fe distributed over both B cation sites

Figure 7 Room temperature ${ }^{57} \mathrm{Fe}$ Mössbauer spectrum of $\mathrm{SrLa}_{2} \mathrm{FeCoSbO}_{9}$ acquired over a velocity range of (a) around $\pm 11.5 \mathrm{~mm} / \mathrm{s}$ and (b) around $\pm 4.8 \mathrm{~mm} / \mathrm{s}$; the spectrum in (b) was fitted with two quadrupole-split doublets of equal area and one possible line-pairing combination (1:3 \& 2:4 in Table 3$)$ is shown. 
Figure 8 (a) Temperature dependence of the dc molar magnetic susceptibility of $\mathrm{SrLa}_{2} \mathrm{FeCoSbO}_{9}$ and the field dependence of the magnetisation per formula unit at (b) 300 and (c) $5 \mathrm{~K}$.

Figure 9 Temperature dependence of (a) the real part and (b) the imaginary part of the ac susceptibility of $\mathrm{SrLa}_{2} \mathrm{FeCoSbO}_{9}$.

Figure 10 Magnetic structure adopted by $\mathrm{SrLa}_{2} \mathrm{FeCoSbO}_{9}$; arrows indicate the direction of ordered magnetic moments at the B sites. Green spheres represent the $2 d$ sites and blue spheres represent the $2 c$ sites.

Figure 11 Observed (red) and calculated (green) time-of-flight neutron diffraction patterns of $\mathrm{SrLa}_{2} \mathrm{FeCoSbO}_{9}$ at $5 \mathrm{~K}$ collected at (a) $2 \theta=34.96^{\circ}$ and (b) $2 \theta=$ $91.30^{\circ}$. A difference curve (purple) is shown and reflection positions are marked. Black bars represent structural reflections and red bars represent magnetic reflections. An arrow indicates the peak with the strongest magnetic contribution. 
Table 1 Refined structural parameters for $\mathrm{SrLa}_{2} \mathrm{FeCoSbO}_{9}$ at 300 and $5 \mathrm{~K}$; space group $P 2_{1} / n$

\begin{tabular}{|c|c|c|c|c|}
\hline$T(\mathrm{~K})$ & & & 300 & 5 \\
\hline$a(\AA)$ & & & $5.6218(6)$ & $5.6091(4)$ \\
\hline$b(\AA)$ & & & $5.6221(6)$ & $5.6148(4)$ \\
\hline$c(\AA)$ & & & $7.9440(8)$ & $7.9279(6)$ \\
\hline$\beta\left(^{\circ}\right)$ & & & $90.050(7)$ & 89.999(9) \\
\hline $\mathrm{R}_{\mathrm{wpr}}$ & & & $2.34 \%$ & $2.63 \%$ \\
\hline$\chi^{2}$ & & & 1.51 & 1.82 \\
\hline $\mathrm{Sr} / \mathrm{La}$ & $4 e$ & Occupancy & $1 / 3 / 2 / 3$ & $1 / 3 / 2 / 3$ \\
\hline & & $x$ & $0.4932(4)$ & $0.4930(3)$ \\
\hline & & $y$ & $0.5262(2)$ & $0.5294(1)$ \\
\hline & & $z$ & $0.2510(9)$ & $0.2504(8)$ \\
\hline & & Uiso $\left(\AA^{2}\right)$ & $0.0123(2)$ & $0.0080(1)$ \\
\hline $\mathrm{Fe}_{1} / \mathrm{Co}$ & $2 d$ & Occupancy & $1 / 3 / 2 / 3$ & $1 / 3 / 2 / 3$ \\
\hline & & Uiso $\left(\AA^{2}\right)$ & $0.0038(7)$ & $0.0023(5)$ \\
\hline $\mathrm{Fe}_{2} / \mathrm{Sb}$ & $2 c$ & Occupancy & $1 / 3 / 2 / 3$ & $1 / 3 / 2 / 3$ \\
\hline & & Uiso $\left(\AA^{2}\right)$ & $0.0051(6)$ & $0.0026(4)$ \\
\hline $\mathrm{O}_{1}$ & $4 e$ & $x$ & $0.2764(7)$ & $0.2757(7)$ \\
\hline & & $y$ & $0.2827(9)$ & $0.2836(9)$ \\
\hline & & $z$ & $0.0316(4)$ & $0.0340(4)$ \\
\hline & & Uiso $\left(\AA^{2}\right)$ & $0.0129(8)$ & $0.0081(7)$ \\
\hline $\mathrm{O}_{2}$ & $4 e$ & $x$ & $0.2143(7)$ & $0.2116(6)$ \\
\hline & & $y$ & $0.7821(8)$ & $0.7831(9)$ \\
\hline & & $Z$ & $0.0405(4)$ & $0.0403(4)$ \\
\hline & & Uiso $\left(\AA^{2}\right)$ & $0.0091(7)$ & $0.0064(6)$ \\
\hline $\mathrm{O}_{3}$ & $4 e$ & $x$ & $0.5723(3)$ & $0.5726(3)$ \\
\hline & & $y$ & $0.9879(3)$ & $0.9866(2)$ \\
\hline & & $Z$ & $0.2531(9)$ & $0.254(1)$ \\
\hline & & Uiso $\left(\AA^{2}\right)$ & $0.0101(3)$ & $0.0070(2)$ \\
\hline
\end{tabular}


Table 2 Selected bond lengths ( $\AA$ ) and bond angles (degrees) in $\mathrm{SrLa}_{2} \mathrm{FeCoSbO}_{9}$ at 300 and 5 $\mathrm{K}$.

\begin{tabular}{|c|c|c|}
\hline & $300 \mathrm{~K}$ & $5 \mathrm{~K}$ \\
\hline $\mathrm{Sr} / \mathrm{La}-\mathrm{O}_{1}$ & $2.530(6)$ & $2.516(6)$ \\
\hline $\mathrm{Sr} / \mathrm{La}-\mathrm{O}_{1}$ & $2.713(6)$ & $2.689(6)$ \\
\hline $\mathrm{Sr} / \mathrm{La}-\mathrm{O}_{1}$ & $2.806(6)$ & $2.805(6)$ \\
\hline $\mathrm{Sr} / \mathrm{La}-\mathrm{O}_{2}$ & $2.705(6)$ & $2.701(6)$ \\
\hline $\mathrm{Sr} / \mathrm{La}-\mathrm{O}_{2}$ & $2.448(6)$ & $2.446(6)$ \\
\hline $\mathrm{Sr} / \mathrm{La}-\mathrm{O}_{2}$ & $2.826(6)$ & $2.810(7)$ \\
\hline $\mathrm{Sr} / \mathrm{La}-\mathrm{O}_{3}$ & $2.632(2)$ & $2.606(1)$ \\
\hline $\mathrm{Sr} / \mathrm{La}-\mathrm{O}_{3}$ & $2.453(3)$ & $2.449(2)$ \\
\hline $\mathrm{Fe}_{1} / \mathrm{Co}-\mathrm{O}_{1}$ & $2.042(5) * 2$ & $2.047(5) * 2$ \\
\hline $\mathrm{Fe}_{1} / \mathrm{Co}-\mathrm{O}_{2}$ & $2.046(4) * 2$ & $2.050(4) * 2$ \\
\hline $\mathrm{Fe}_{1} / \mathrm{Co}-\mathrm{O}_{3}$ & $2.052(7) * 2$ & $2.052(8) * 2$ \\
\hline $\mathrm{Fe}_{2} / \mathrm{Sb}-\mathrm{O}_{1}$ & $1.992(5) * 2$ & $1.985(5) * 2$ \\
\hline $\mathrm{Fe}_{2} / \mathrm{Sb}-\mathrm{O}_{2}$ & $2.018(4) * 2$ & $2.010(4) * 2$ \\
\hline $\mathrm{Fe}_{2} / \mathrm{Sb}-\mathrm{O}_{3}$ & $2.004(7) * 2$ & $1.998(8) * 2$ \\
\hline $\mathrm{O}_{1}-\mathrm{Fe}_{1} / \mathrm{Co}-\mathrm{O}_{2}$ & $87.9(3) * 2$ & $87.5(2) * 2$ \\
\hline $\mathrm{O}_{1}-\mathrm{Fe}_{1} / \mathrm{Co}-\mathrm{O}_{3}$ & $88.5(1) * 2$ & $88.8(1) * 2$ \\
\hline $\mathrm{O}_{2}-\mathrm{Fe}_{1} / \mathrm{Co}-\mathrm{O}_{3}$ & $88.9(1) * 2$ & $90.0(1) * 2$ \\
\hline $\mathrm{O}_{1}-\mathrm{Fe}_{2} / \mathrm{Sb}-\mathrm{O}_{2}$ & $89.8(3) * 2$ & $89.9(2) * 2$ \\
\hline $\mathrm{O}_{1}-\mathrm{Fe}_{2} / \mathrm{Sb}-\mathrm{O}_{3}$ & $89.2(1) * 2$ & $89.8(1) * 2$ \\
\hline $\mathrm{O}_{2}-\mathrm{Fe}_{2} / \mathrm{Sb}-\mathrm{O}_{3}$ & $89.6(1) * 2$ & $89.7(1) * 2$ \\
\hline $\mathrm{Fe}_{1} / \mathrm{Co}-\mathrm{O}_{1}-\mathrm{Fe}_{2} / \mathrm{Sb}$ & $160.4(2)$ & $159.5(2)$ \\
\hline $\mathrm{Fe}_{1} / \mathrm{Co}-\mathrm{O}_{2}-\mathrm{Fe}_{2} / \mathrm{Sb}$ & $156.1(2)$ & $155.7(2)$ \\
\hline $\mathrm{Fe}_{1} / \mathrm{Co}-\mathrm{O}_{3}-\mathrm{Fe}_{2} / \mathrm{Sb}$ & 156.6(1) & 156.38(9) \\
\hline
\end{tabular}


Table 3 Mössbauer hyperfine parameters, Isomer Shift (IS) relative to $\alpha$-Fe, and Quadrupole Splitting (QS), obtained from fits to the narrower-velocity-range room temperature spectrum of $\mathrm{SrLa}_{2} \mathrm{FeCoSbO}_{9}$ for the three possible line-pairing combinations discussed in the text. (The line numbering, 1 to 4 , is in order of increasingly positive velocity).

\begin{tabular}{lll}
\hline Line Pairings & QS (mm/s) & IS (mm/s) \\
\hline $1: 2 \& 3: 4$ & $0.182(6) \& 0.191(4)$ & $+0.096(2) \&+0.710(2)$ \\
$1: 3 \& 2: 4$ & $0.609(4) \& 0.619(4)$ & $+0.310(3) \&+0.496(3)$ \\
$1: 4 \& 2: 3$ & $0.801(4) \& 0.428(4)$ & $+0.404(3) \&+0.400(3)$ \\
\hline
\end{tabular}




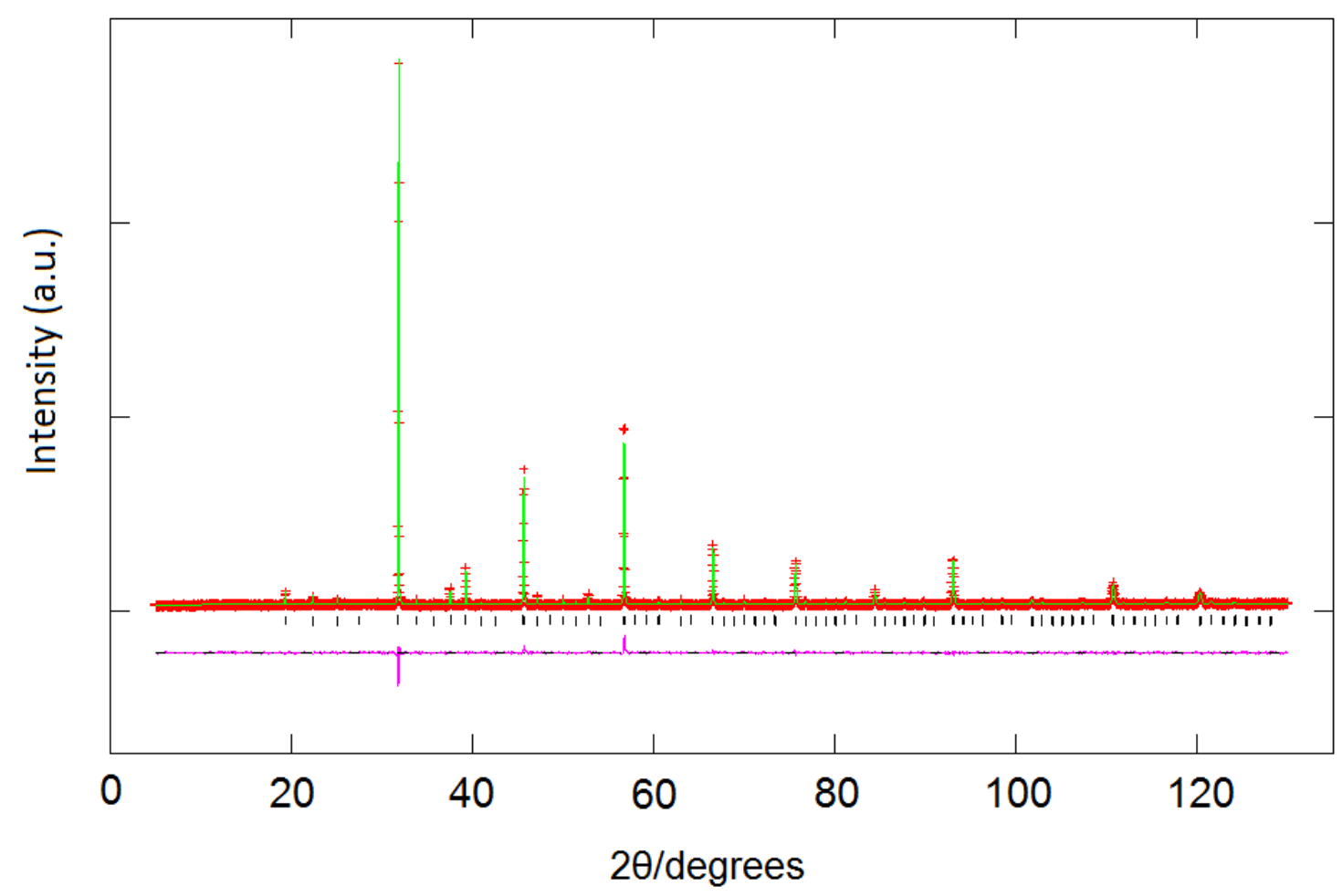

Figure 1 

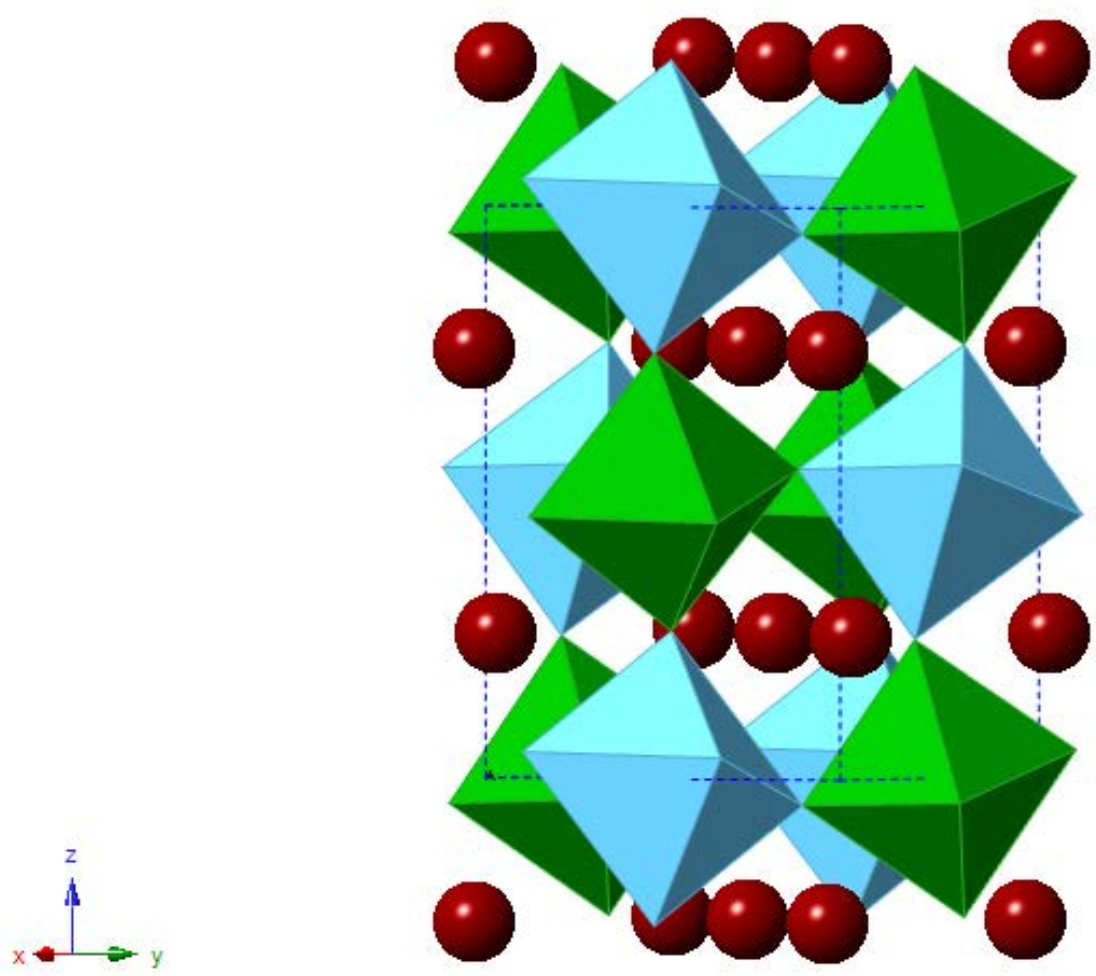

Figure 2 
(a)

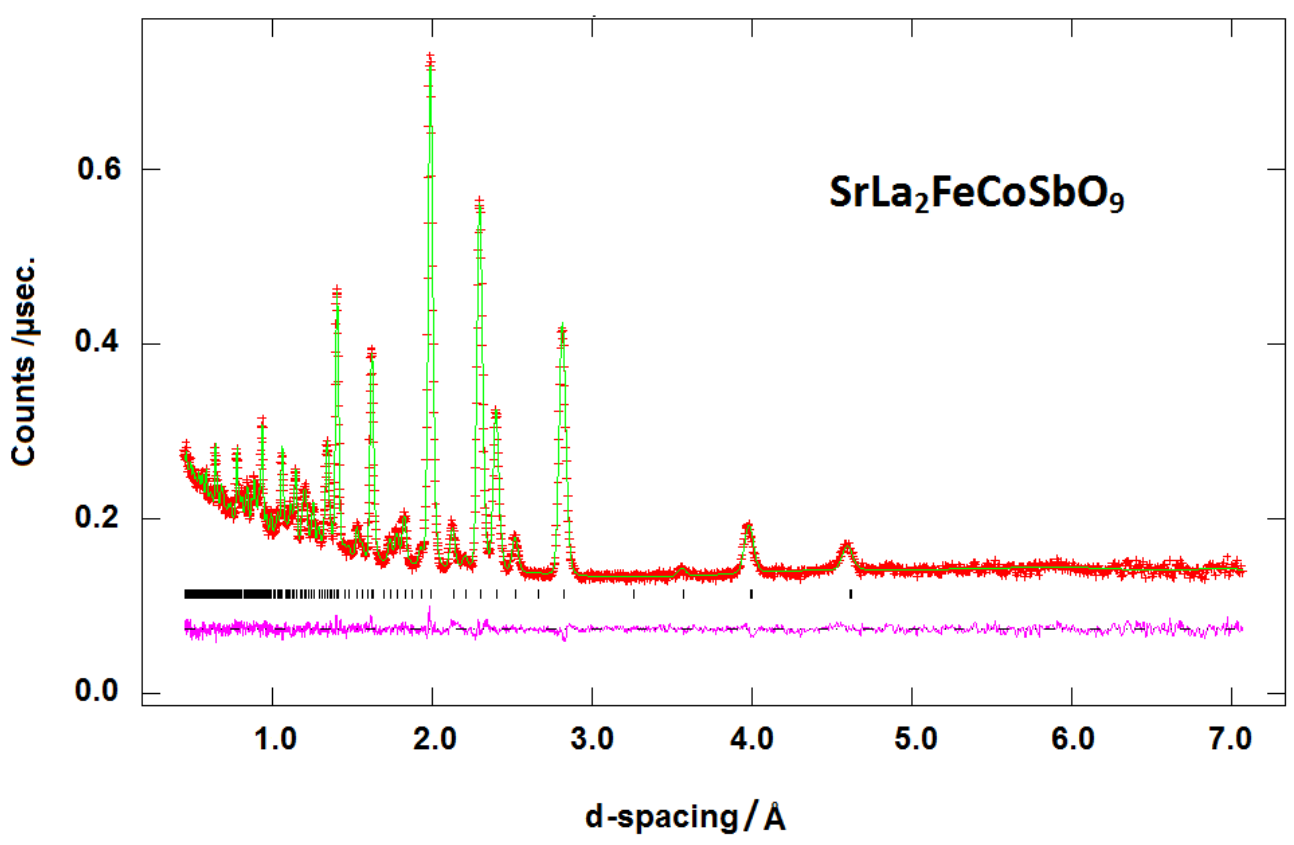

(b)

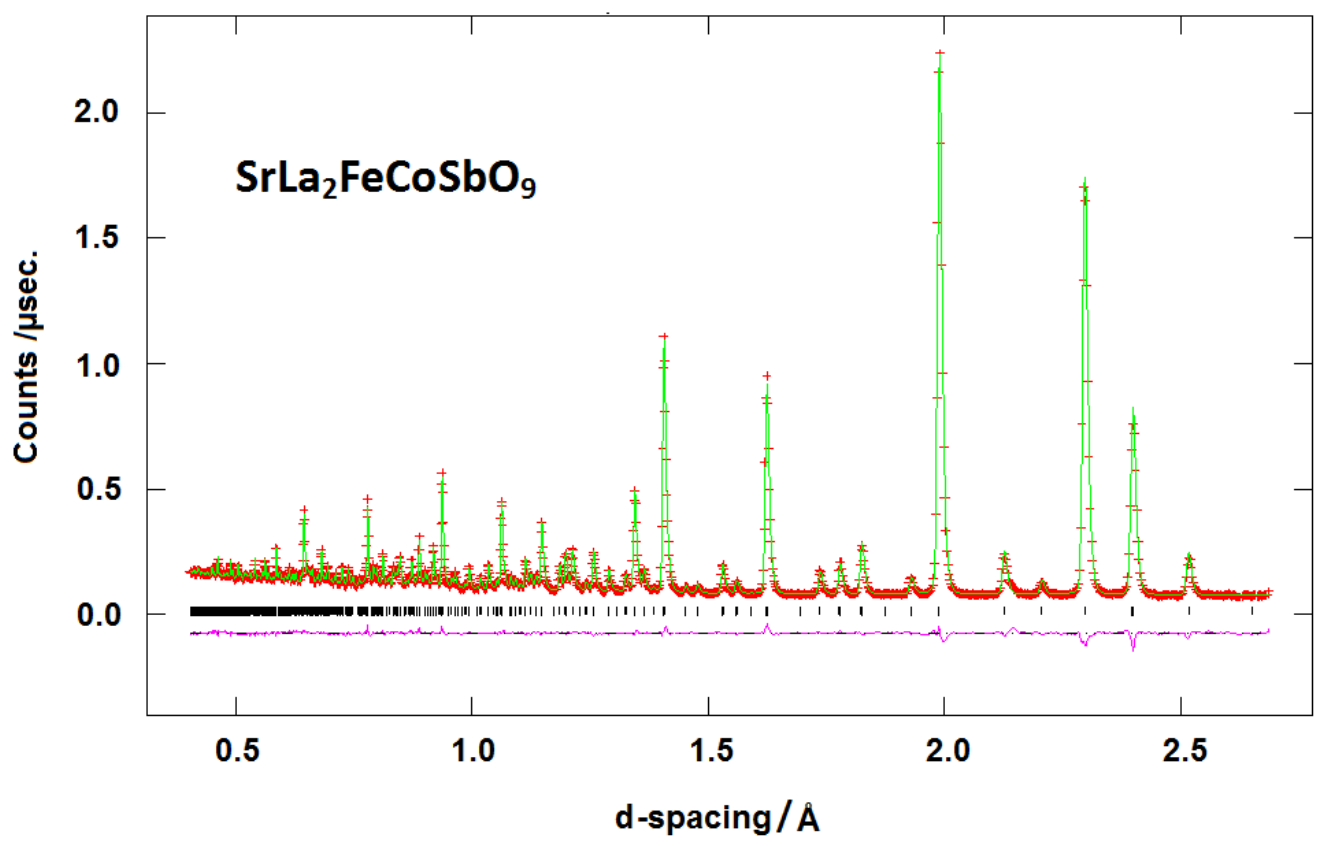

Figure 3 
Figure 4. 


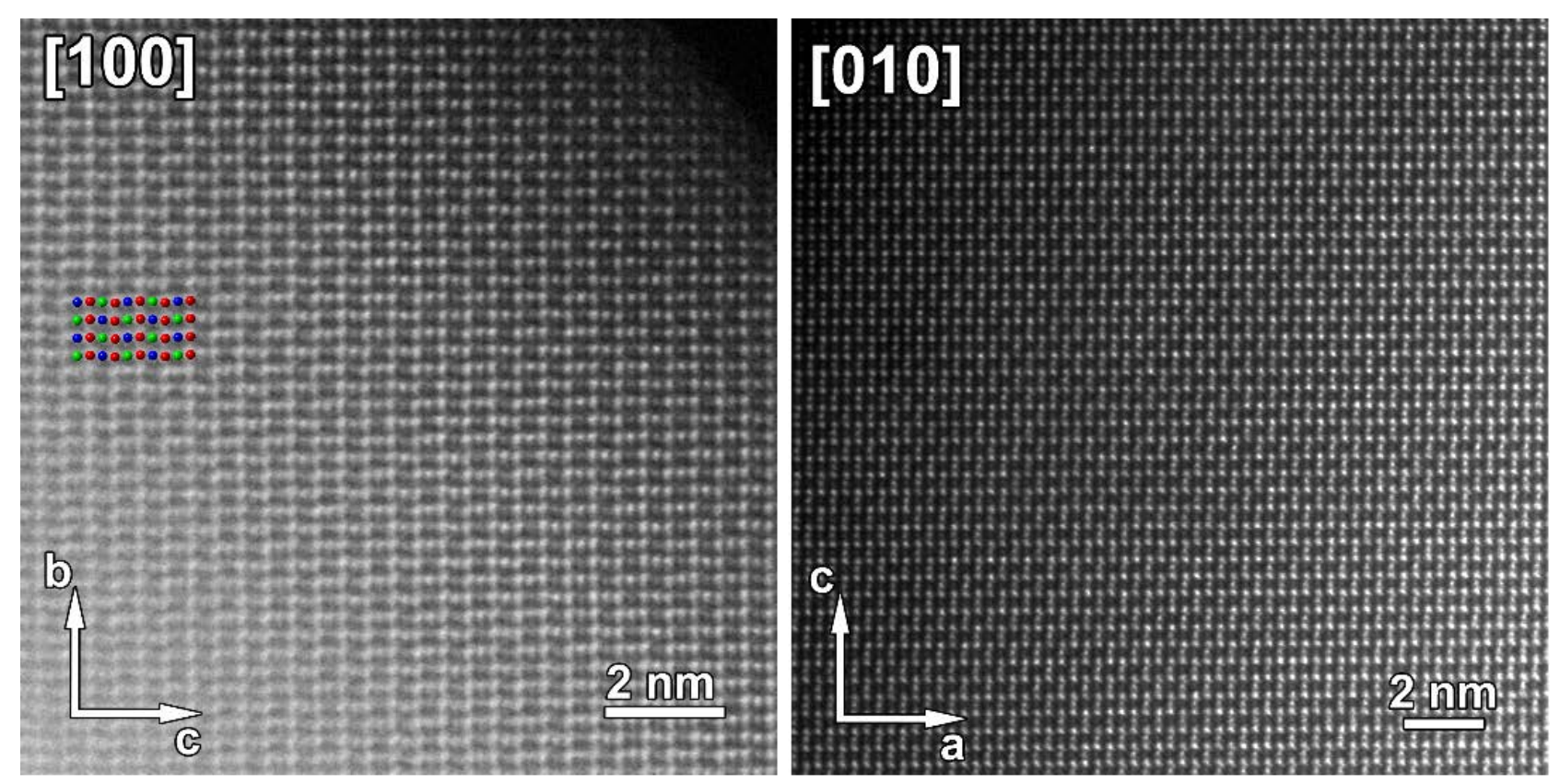

Figure 5. 


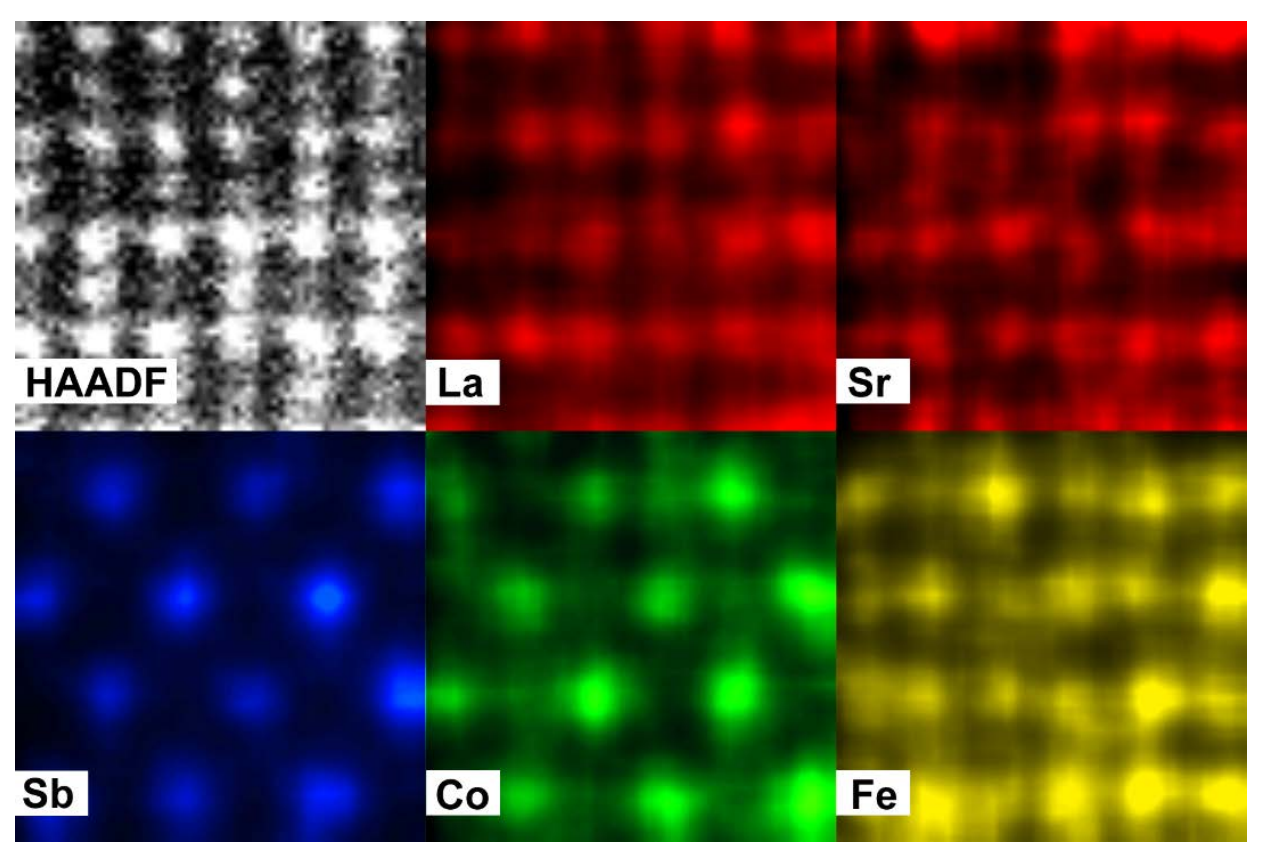

Figure 6. 

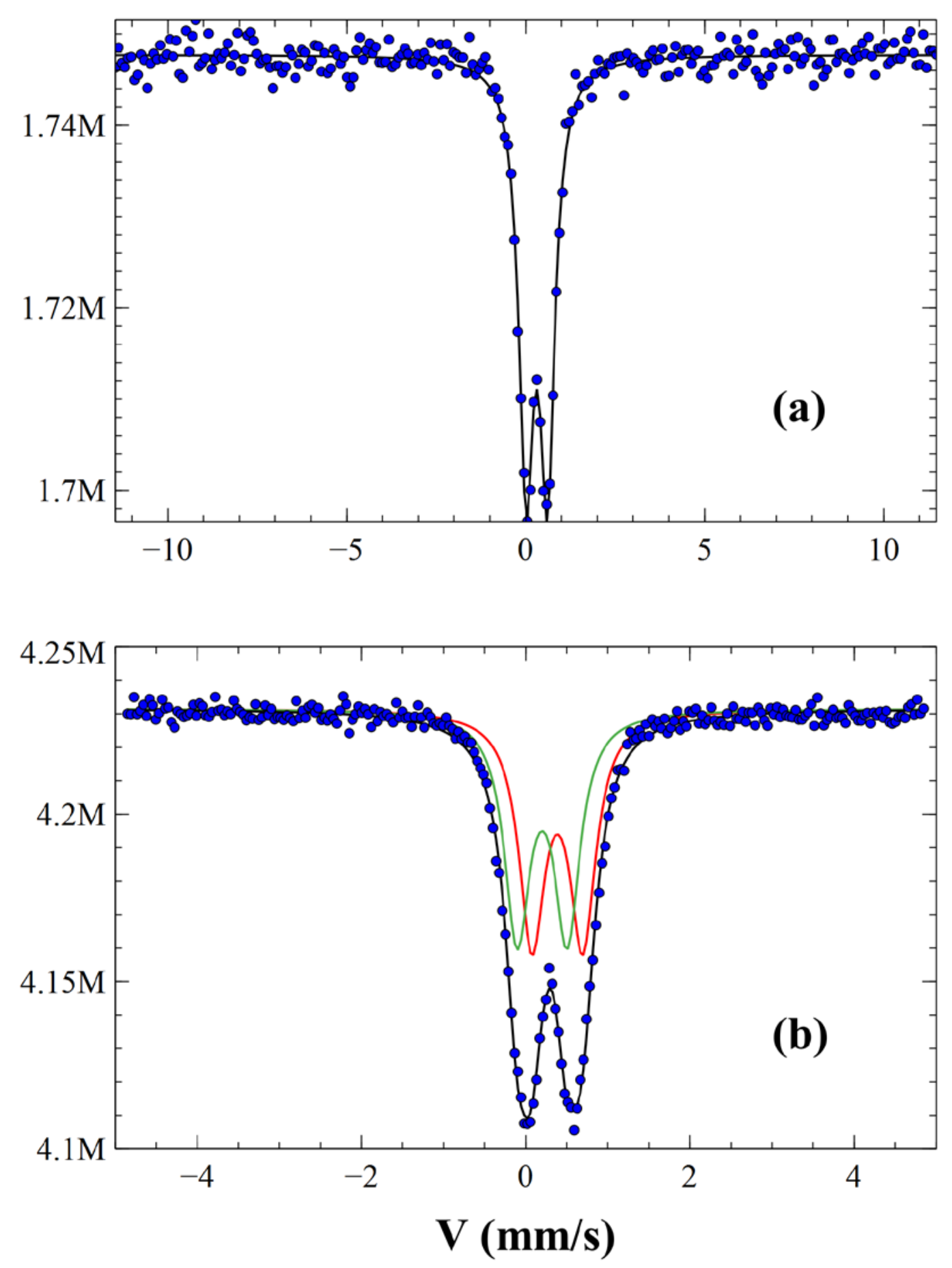

Figure 7 
(a)

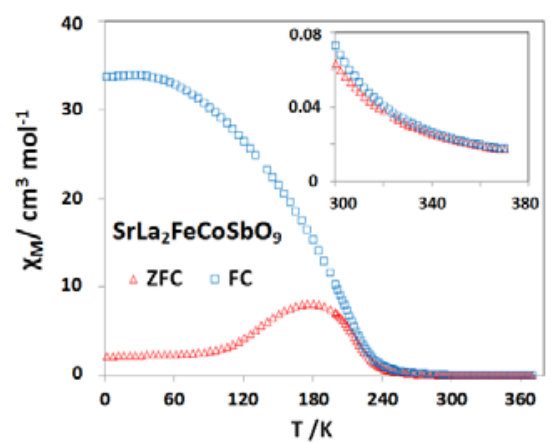

(b)

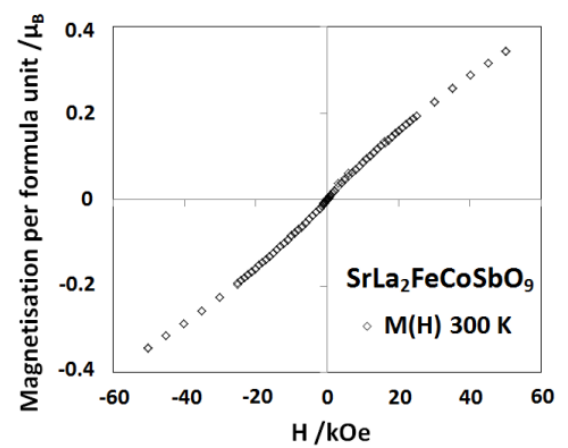

(c)

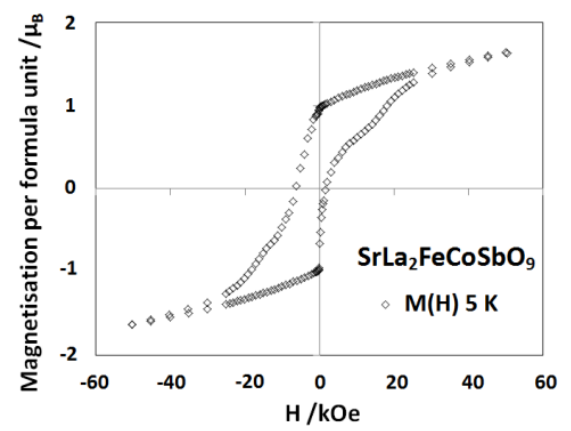

Figure 8 
(a)

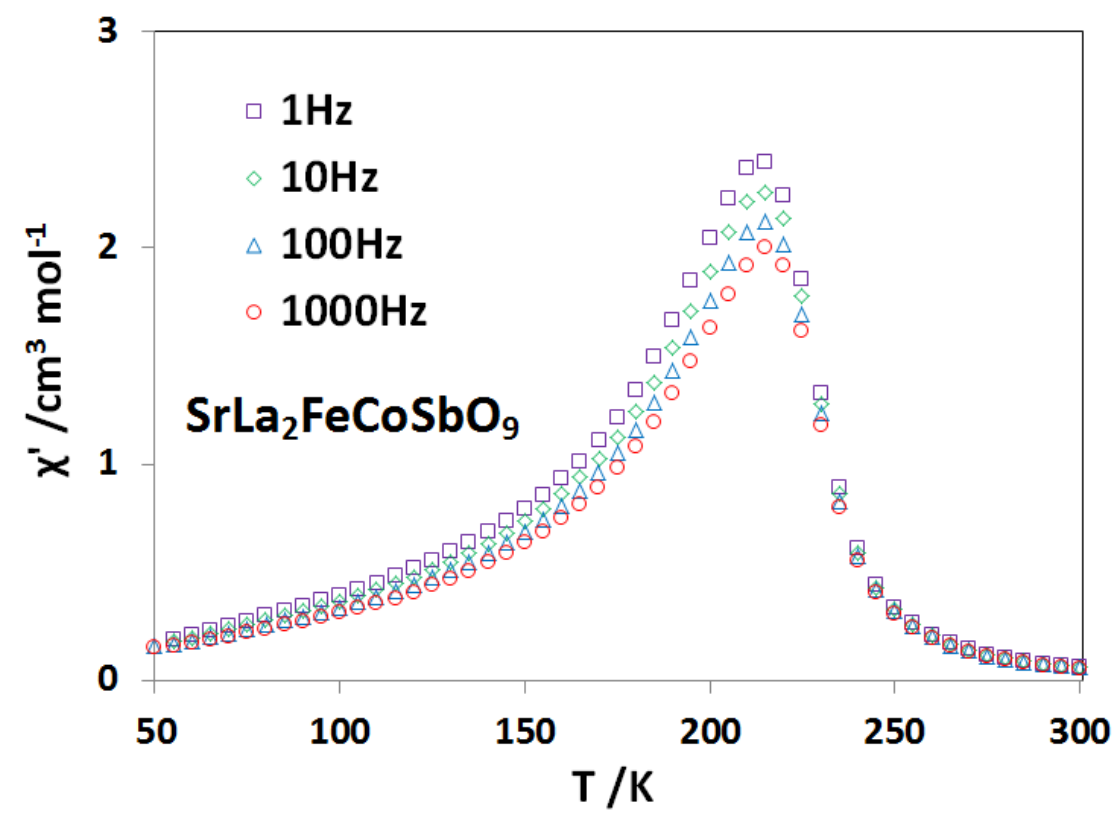

(b)

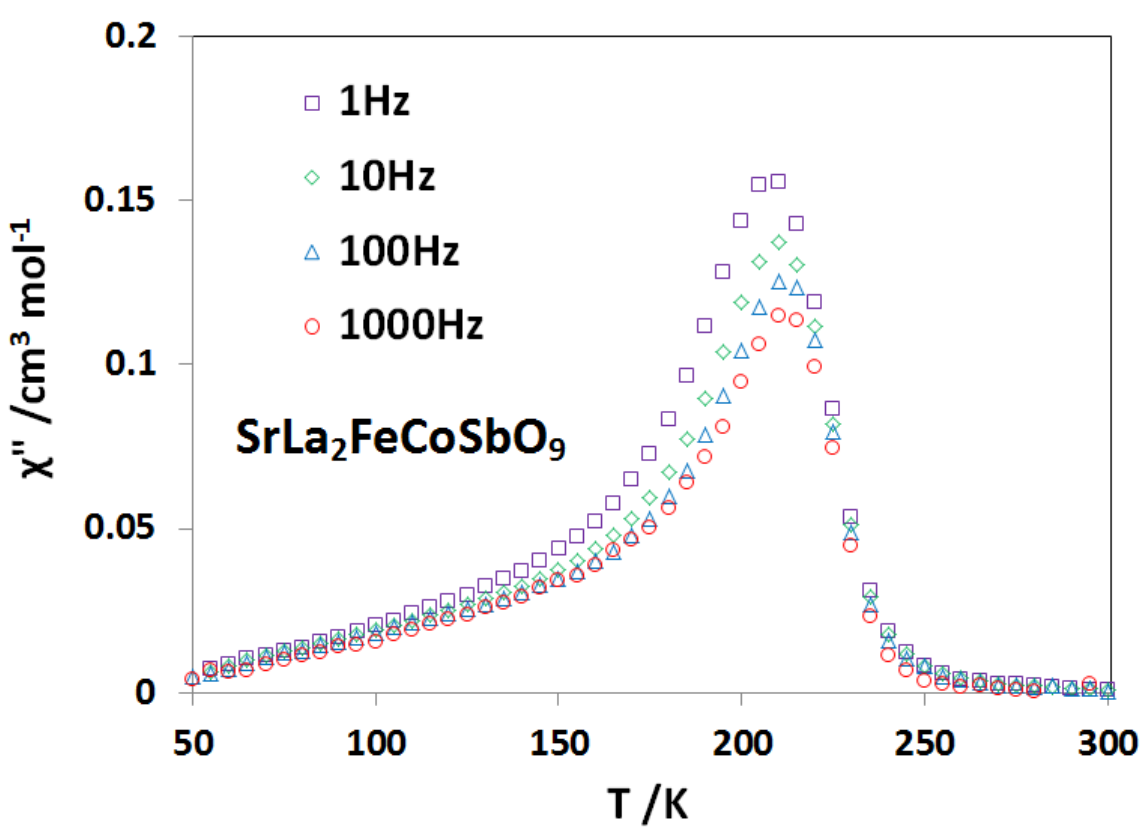

Figure 9 


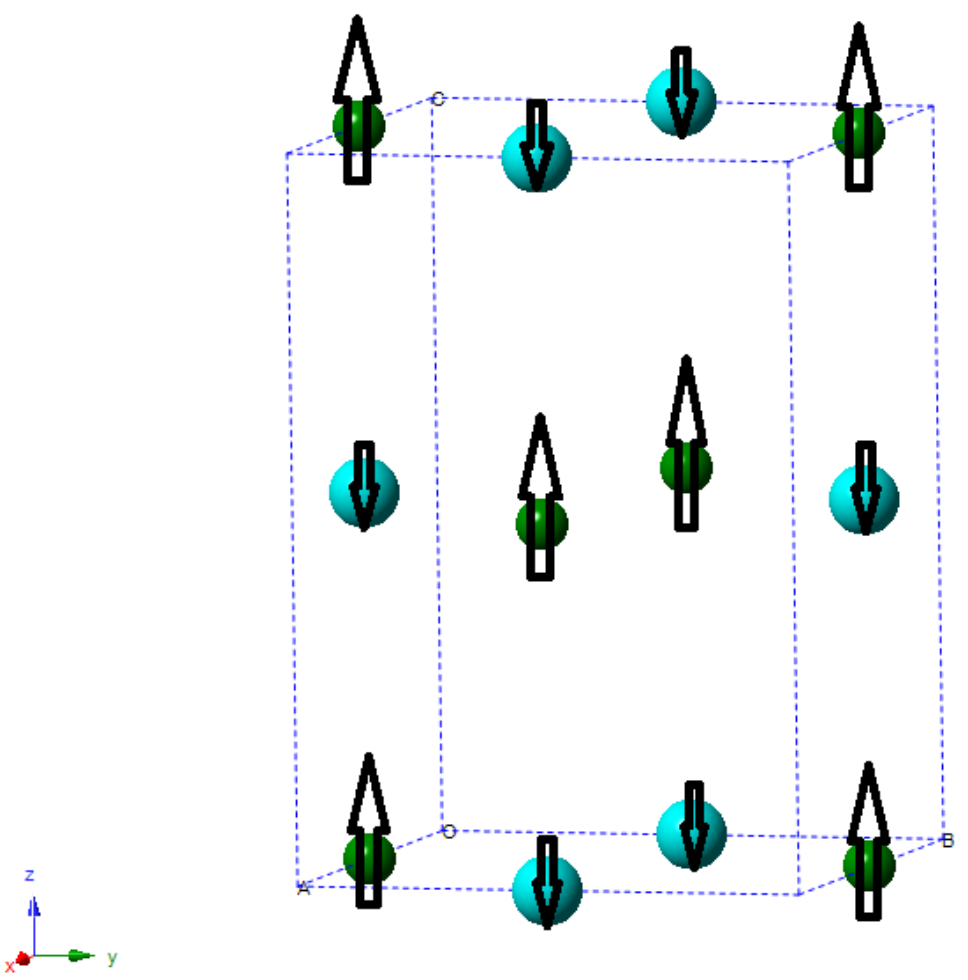

Figure 10 
(a)

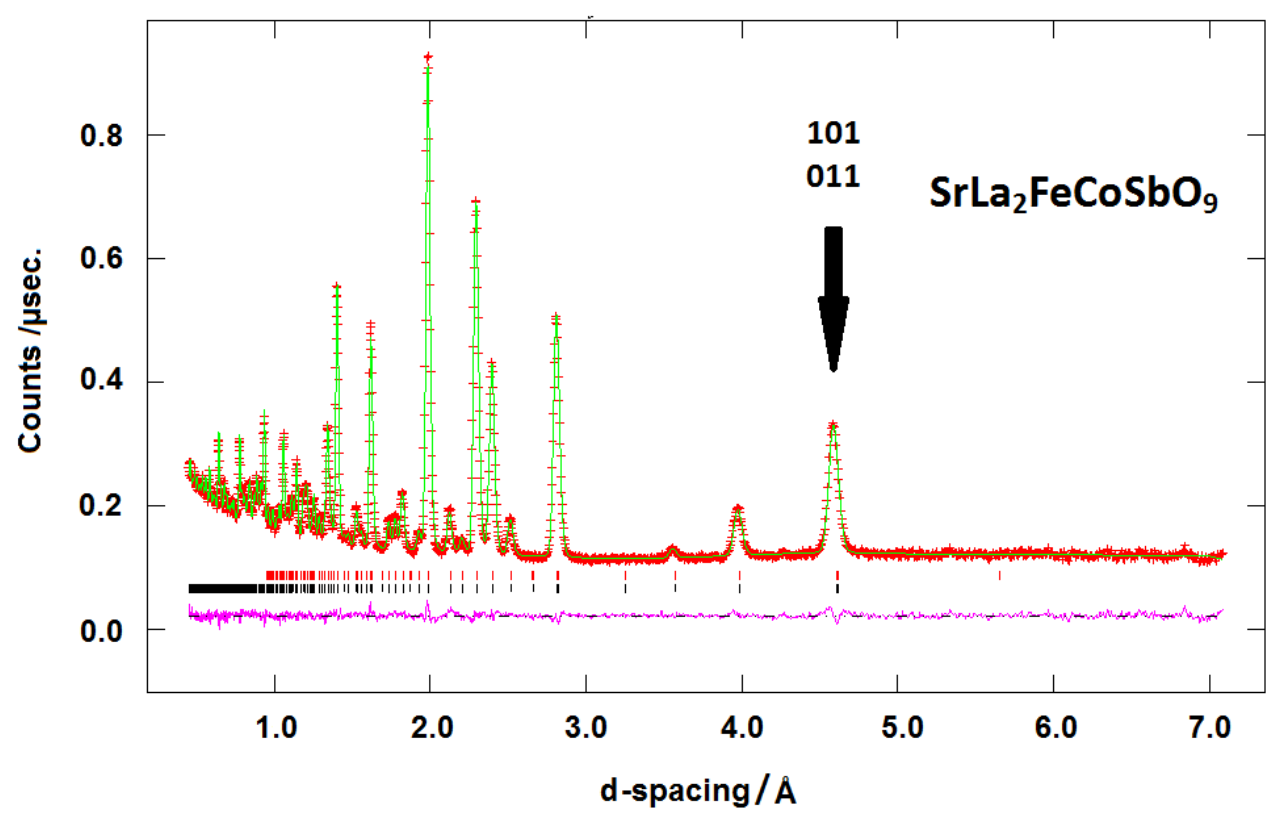

(b)

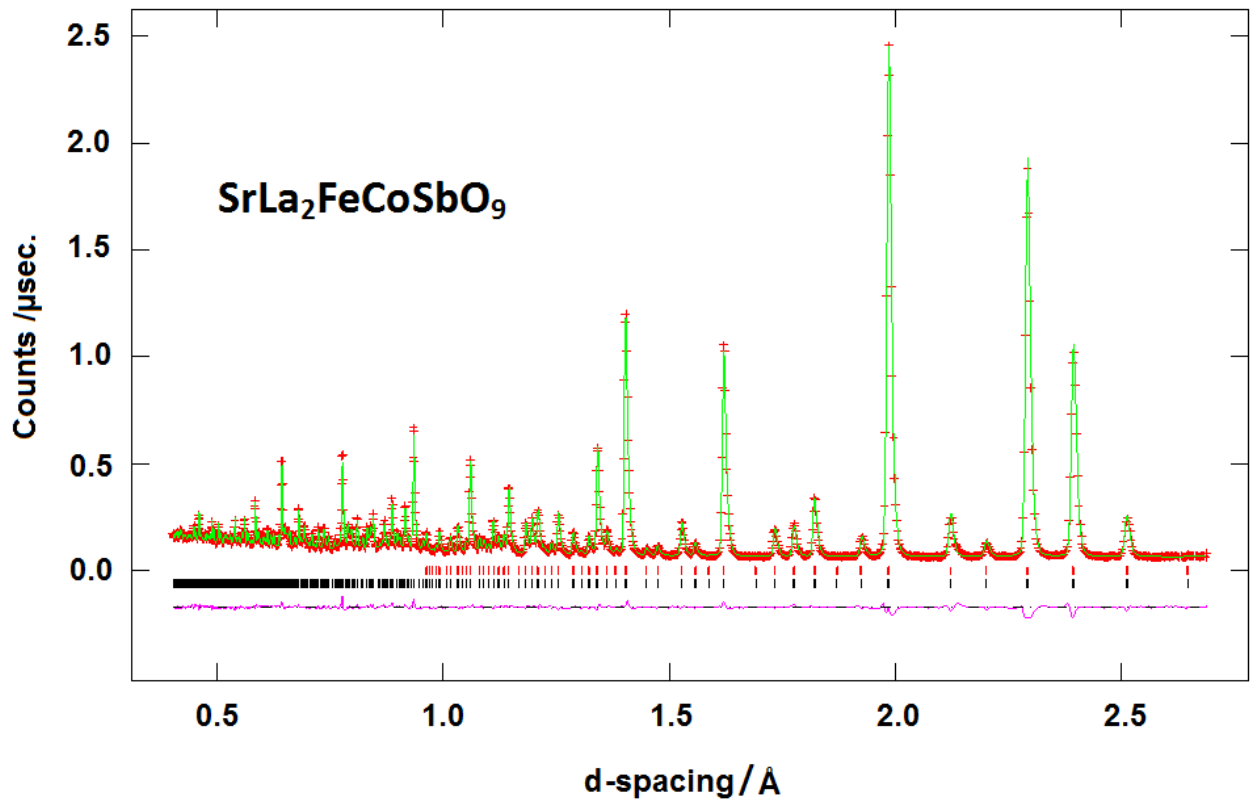

Figure 11 


\section{For Table of Contents only}

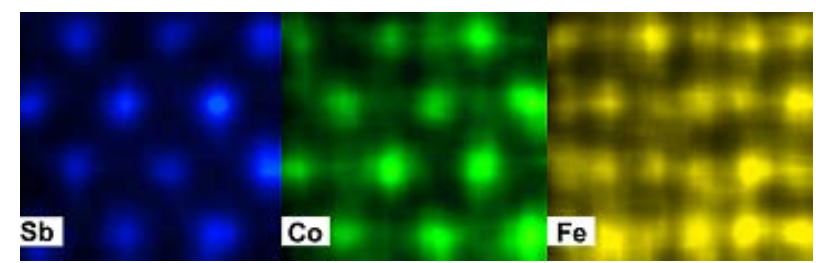

The pattern of cation ordering over the two crystallographically-distinct six-coordinate sites in the monoclinic perovskite $\mathrm{SrLa}_{2} \mathrm{FeCoSbO}_{9}$ results in the formation of a ferrimagnetic phase below $215 \mathrm{~K}$. 